\title{
LINC00221 silencing prevents the progression of hepatocellular carcinoma through let-7a-5p-targeted inhibition of MMP11
}

Lin Yang ${ }^{1+}$, Hailong $\mathrm{Si}^{2 \dagger}$, Meng Ma, Yu Fang ${ }^{3}$, Yina Jiang ${ }^{3}$, Jintao Wang ${ }^{1}$, Cheng Zhang ${ }^{1 *}$ and Haijuan Xiao ${ }^{2^{*}}$ (D)

\begin{abstract}
Background: Microarray profiles of hepatocellular carcinoma (HCC) identified that long intergenic noncoding RNA 00221 (LINC00221) was upregulated. Herein, we aimed to identify the functional significance and underlying mechanisms of LINC00221 in HCC.

Methods and results: Human HCC samples had increased expression of LINC00221. Effects of LINC00221 on HCC cellular functions were analyzed using gain- and loss-function approaches. LINC00221 knockdown repressed HCC cell growth, migration, and invasion and enhanced their apoptosis. This anti-tumor effect was validated in vivo. Online prediction showed the potential binding relationship between LINC00221 and let-7a-5p, as well as that between let-7a-5p and matrix metalloproteinase 11 (MMP11). The results of luciferase, RNA immunoprecipitation, and RNA pulldown assays identified that LINC00221 interacted with let-7a-5p to increase expression of MMP11. Furthermore, we demonstrated that LINC00221 silencing increased let-7a-5p and inhibited MMP11 expression, thereby delaying the progression of $\mathrm{HCC}$ in vitro.
\end{abstract}

Conclusions: Silencing of LINC00221 could prevent HCC progression via upregulating let-7a-5p and downregulating MMP11. As such, LINC00221 inhibition presents a promising antitumor strategy for the treatment of HCC.

Keywords: Hepatocellular carcinoma, Long noncoding RNA LINC00221, Let-7a-5p, Matrix metalloproteinase-11, Cell cycle, Cell migration

\section{Background}

Hepatocellular carcinoma (HCC) is the predominant histological subtype among primary liver cancers, and ranks 2nd among cancer-related deaths in China [1, 2]. HCC usually occurs in a condition of chronic inflammation [3]. Most cases of HCC arise in developing countries, but the

\footnotetext{
*Correspondence: ztx3716336@126.com; xhjdoc@qq.com

${ }^{\dagger}$ Lin Yang and Hailong Si contributed equally to this work

${ }^{1}$ Department of Hepatobiliary Surgery, Shaanxi Province, Xianyang

Central Hospital, No. 78, Renmin East Road, Weicheng District,

Xianyang 712000, People's Republic of China

${ }^{2}$ Department of Oncology, Shaanxi Province, Affiliated Hospital

of the Shaanxi University of Traditional Chinese Medicine, No. 2, Weiyang

West Road, Xianyang 712000, People's Republic of China

Full list of author information is available at the end of the article
}

global incidence is increasing in parallel with its risk factors, namely obesity, alcoholism, as well as hepatitis $C$ [4]. The prospects for long-term survival with HCC remains poor [5], since most available treatment protocols do little to alter the poor prognosis, and only one third of cases are eligible for curative treatments [6]. Therefore, there is an urgent need to obtain a better understanding of the genetic and physiological factors that mediate the progression of HCC.

Multiple long non-coding RNAs (lncRNAs) possess the vital potential to control cellular process involved in the pathophysiology of HCC [7]. LncRNAs are a group of non-protein-coding transcripts with a length of 200 or more nucleotides; dysregulation of lncRNAs possibly contributes to development and progression of 
tumors [8]. Long intergenic noncoding RNA 00,221 (LINC00221), also known as NCRNA00221 [9], is an lncRNA recognized to be a potential prognostic biomarker for HCC [10]. However, its involvement in HCC progression remains to be established. LncRNAs have been widely identified to function as competitive endogenous RNAs (ceRNAs) or sponges of microRNAs (miRNAs), thus mediating effects on the post-transcription regulation of mRNAs [11]. For example, a previous study has suggested that the lncRNA Ras suppressor protein 1 pseudogene 2 (RSU1P2) mediates gene expression in cervical cancer by functioning as a ceRNA of let-7a [12]. Importantly, miRNA let-7a exhibits low expression levels in HCC cells [13]. Other studies show that silencing of IncRNA LINC01561 can suppress proliferation while enhancing the apoptosis of $\mathrm{BrCa}$ cells by increasing miR-145-5p and decreasing matrix metalloproteinase 11 (MMP11) expression [14]. MMP11 acts as a regulator of HCC proliferation and metastasis [15]. The results from the RNA22, Starbase, mirDIP, and miRDB databases, predicted that LINC00221 could bind to let-7a-5p, which in turn could bind to MMP11. Therefore, we hypothesized that LINC00221 might have a crucial modulatory effect on the growth of HCC cells through the let-7a-5p/ MMP11 axis.

\section{Methods}

\section{Microarray-based RNA expression profiling}

We downloaded microarray profiles and annotation probe files related to HCC from the Gene Expression Omnibus (GEO) database (Table 1). The Affy package of $\mathrm{R}$ software was employed to perform background correction and normalization processing for the microarray data [16]. Using $\mid \log 2$ (fold change) $\mid>1$ and value $<0.05$ as threshold criteria, the Limma package (http://master.bioconductor.org/packages/relea se/bioc/html/ limma.html) was applied to screen out the differentially expressed lncRNAs/miRNAs/mRNAs. HCC-related lncRNAs were screened from the GSE33006 microarray, which contained data from three pairs of HCC tissue samples and adjacent normal liver tissues. The downstream regulatory miRNAs of candidate lncRNA were predicted using the RNA22 database, which were intersected with the down-regulated miRNAs in HCC screened from GSE12717 to select candidate miRNAs. The target genes of candidate miRNAs were obtained from the Starbase, mirDIP, and miRDB databases, and then were intersected with up-regulated genes in HCC from the GSE89377 and GSE117361 microarrays using the Venn website. Data of HCC prognosis and HCCrelated gene expression from The Cancer Genome Atlas (TCGA) database were further analyzed using $\mathrm{R}$ software. The package edge $R$ of $R$ software was applied for differential analyses of the transcriptome profiling data [17], and false positive discovery (FDR) correction was utilized with the p-value defined by the package multitest. The differentially expressed genes (DEGs) were screen out with the threshold of FDR $<0.05$ and $\mid \log 2$ (fold change) $\mid>2$.

\section{Study subjects}

The HCC tissues as well as the adjacent non-tumor tissue (adjacent to the tumor margin at a distance greater than $2 \mathrm{~cm}$ ) were collected from $45 \mathrm{HCC}$ patients and subsequently stored in liquid nitrogen. The enrolled patients included 26 males and 19 females (aged 32-69 years), with 17 cases having a tumor size $\leq 5 \mathrm{~cm}$ and the remaining 28 cases with tumor size $>5 \mathrm{~cm} ; 15$ cases had multiple tumors and 30 cases had a single tumor. The clinical stage of all patients was determined based on the EdmondsonSteiner grade [18], with 21 cases regarded as grade I/ II and 24 cases as grade III. Based on the Tumor-NodeMetastasis (TNM) staging classification of Modified Union for International Cancer Control (mUICC) stage [19], 28 cases were confirmed to be stage I/II and 17 cases as stage IIIa. The inclusion criteria were based on the following clinical manifestations: (1) alpha-fetoprotein (AFP) level maintained $\geq 200 \mu \mathrm{g} / \mathrm{mL}$ for one month; (2) AFP level maintained $\leq 200 \mu \mathrm{g} / \mathrm{mL}$ for two months [20]; (3) The diagnosis of HCC was confirmed by means of abdominal CT scans on a Philips Brilliance CT 64-channel scanner (Philips Medical Systems, Eindhoven, the Netherlands) [21]. The exclusion criteria were as follows: patients who had a history of chemotherapy or radiotherapy, or who had participated in other clinical trials (including placebo-controlled trials) within three months before the experiment, had received immunotherapy, or

Table 1 HCC-related microarray profiles

\begin{tabular}{ll}
\hline GSE & Sample size \\
\hline GSE33006 & 3 tumor tissue samples; 3 adjacent normal tissue samples \\
GSE12717 & 10 tumor tissue samples; 6 adjacent normal tissue samples \\
GSE89377 & 35 tumor tissue samples; 13 adjacent normal tissue samples \\
GSE117361 & 2 tumor tissue samples; 2 adjacent normal tissue samples \\
\hline
\end{tabular}


suffered from hepatitis B virus (HBV) or primary biliary cirrhosis [22].

\section{Fluorescence in situ hybridization (FISH) assay}

A FISH assay was conducted to identify the subcellular localization of LINC00221 in the HCC cells [23]. HCC cells were seeded in a 24-well plate at a concentration of $5 \times 10^{3}$ cells per well. After $24 \mathrm{~h}$, the supernatant was removed, and the cells were fixed with $4 \%$ paraformaldehyde, permeated in $0.1 \%$ Triton $\mathrm{X}-100$, and then treated with pre-hybridization solution at $37{ }^{\circ} \mathrm{C}$. The doublestranded DNA probe was incubated in a water bath at $75{ }^{\circ} \mathrm{C}$ for $5 \mathrm{~min}$ and then immediately placed on ice for denaturation. 5-10 min later, the prepared chromosome slide specimen was denatured, and $10 \mu \mathrm{L}$ denatured or pre-annealed biotin-labelled LINC00221 probe (Shanghai Gefan Biotechnology Co., Ltd., Shanghai, China) was dropped on the denatured and dehydrated slide specimen. The specimen was then covered with an $18 \times 18$ coverslip, sealed with parafilm, and was placed in a humidified cassette at $37{ }^{\circ} \mathrm{C}$ to hybridize overnight (approximately 15-17 h). The next day, elution was then carried out to remove non-specifically bound probes, followed by hybridization signal amplification. Ten minutes later, samples were analyzed under an Axio Observer A1 inverted microscope (Carl Zeiss, Jena, Germany).

\section{Cell transfection}

The human normal liver cell line (HL-7702) and three HCC cell lines (MHCC97-H, Huh7, and Hep3B) obtained from Shanghai Institutes for Biological Sciences, Chinese Academy of Sciences (Shanghai, China) were employed for this study. The cells were incubated with Dulbecco's modified Eagle's medium supplemented with $20 \%$ fetal bovine serum, penicillin $(50 \mathrm{U} / \mathrm{mL})$ and streptomycin $(50 \mathrm{U} / \mathrm{mL})$ at $37{ }^{\circ} \mathrm{C}$ with $5 \% \mathrm{CO}_{2}$, followed by sub-culture until the cells attained a logarithmic growth rate. HL-7702, MHCC97-H, Huh7, and Hep3B cells were incubated in a 6 -well plate until attaining $80 \%$ confluence. The cells at passage three were utilized for cell line selection. Expression patterns of LINC00221 were determined by reverse transcription-quantitative polymerase chain reaction (RT-qPCR). Next, the cell lines MHCC97-H and Huh7 with high LINC00221 expression were assigned into blank (cells without transfection), si-LINC00221 (cells transfected with siRNA against LINC00221), and si-negative control (NC) groups (cells transfected with scramble siRNA). Lipofectamine 2000 (Invitrogen Inc., Carlsbad, CA) was employed for cell transfection.

According to the sequence information for LINC00221 (NR_122034.1) in the Genebank, we designed three LINC00221 sequences. After successful construction of the recombinant plasmid and verification by sequencing, the plasmid was extracted, and the cell concentration determined prior to preservation at $-20{ }^{\circ} \mathrm{C}$ for later use. Cells $\left(5 \times 10^{3}\right.$ cells/well $)$ were allowed to incubate in a 6 -well plate for $24 \mathrm{~h}$ and subsequently transfected using Lipofectamine 2000. After a 48-h transfection period, transfection efficiency was visualized under a microscope (CFM-500E/CFM-500Z, Changfang Optical Instruments Co., Ltd., Shanghai, China).

\section{RT-qPCR}

Total RNA was extracted using an RNA extraction kit (Takara Biotechnology Ltd., Dalian, China) based on the Trizol method. The absorbance (A) at $260 \mathrm{~nm}$ and $280 \mathrm{~nm}$ was measured with a spectrophotometer (PHLES, China). The high quality of the RNA was confirmed by an A260/A280 ratio in the range 1.9-2.0. The RNA reverse transcription was conducted with the application of TaqMan microRNA assay RT primer (4427975, Applied Biosystems, Foster City, CA) and Primescript RT reagent kits (rr047a, Takara, Tokyo, Japan). The primers were designed and synthesized by Takara (Table 2). GAPDH was used as internal reference for LINC00221, while U6 was used for let-7a-5p. PCR was conducted on an ABI7500 quantitative PCR instrument (Applied Biosystems). The reaction conditions consisted of pre-denaturation at $95^{\circ} \mathrm{C}$ for $10 \mathrm{~min}, 40$ cycles of $10 \mathrm{~s}$ denaturation at $95{ }^{\circ} \mathrm{C}, 20 \mathrm{~s}$ annealing at $60{ }^{\circ} \mathrm{C}$, and $34 \mathrm{~s}$ extension at $72{ }^{\circ} \mathrm{C}$. The $2^{-\Delta \Delta \mathrm{Ct}}$ method was applied to determine the relative expression of the target. $\Delta \Delta \mathrm{Ct}=\Delta \mathrm{Ct}$ (experimental group) $-\Delta \mathrm{Ct}$ (control group); $\Delta \mathrm{Ct}=\mathrm{Ct}$ (target gene) $-\mathrm{Ct}$ (internal control).

\section{Western blot analysis}

The total protein extraction from tissues or cells was conducted with radioimmunoprecipitation assay (RIPA) lysis buffer (P0013c, Beyotime Biotechnology, Shanghai, China) containing phenyhnethylsulfonyl fluoride (PMSF).

Table 2 Primer sequences for RT-qPCR

\begin{tabular}{ll}
\hline Target & Sequence \\
\hline LINC00221 & Forward: 5'-TATGTGGTACAGGGTTGGGC-3' \\
& Reverse: 5'-TGCAGAGCCAACTCTCCTTC-3' \\
GAPDH & Forward: 5'-GGAGCGAGATCCCTCCAAAAT-3' \\
& Reverse: 5'-GGCTGTTGTCATACTTCTCATGG-3' \\
let-7a-5p & Forward: 5'-UGAGGUAGUAGGUUGUAUAGUU-3' \\
& Reverse: 5'-CAGTGCGTGTCGTGGAGT-3' \\
U6 & Forward: 5'-CTCGCTTCGGCAGCACA-3' \\
& Reverse: 5'-AACGCTTCACGAATTTGCGT-3'
\end{tabular}

LINC00221 long intergenic noncoding RNA 00221, GAPDH glyceraldehyde3-phosphate dehydrogenase, $R T-q P C R$ reverse transcription-quantitative polymerase chain reaction 
The supernatant was incubated on ice for $30 \mathrm{~min}$, and centrifuged at $4{ }^{\circ} \mathrm{C}$ and $8000 \mathrm{~g}$ for $10 \mathrm{~min}$, followed by bicinchoninic acid (BCA) protein assay (CWBio, Beijing, China). The extracted proteins were stored at $-80{ }^{\circ} \mathrm{C}$ after packaging. The proteins were separated by sodium dodecyl sulfate-polyacrylamide gel electrophoresis (SDS-PAGE) for $1 \mathrm{~h}$, transferred onto nitrocellulose membranes, and then blocked with 5\% skimmed milk (PBS) for $2 \mathrm{~h}$. The membranes were incubated for $30 \mathrm{~min}$ at ambient temperature with rabbit polyclonal antibodies MMP11 (1:1000, ab119284), Bcl-2 (1:1000, ab182858), Cyclin D1 (1:1000, ab40754), CDK4 (1:1000, ab199728), Bax (1:1000, ab182733), and GAPDH (ab9485, 1:2500) (Abcam, Cambridge, UK). HRP-coupled antibody to immunoglobulin G (IgG) (A21020, 1:5000, AmyJet Scientific Inc., Wuhan, China) was loaded for 1 -h incubation. The immunoblots were subsequently developed using enhanced chemiluminescence reagent (BB-3501, Amersham Biosciences, Piscataway, NJ), and imaged on the gel imager. An imaging system (Bio-Rad Inc., Hercules, CA) was utilized for gray value analysis with the application of Quantity One v4.6.2 software [24].

\section{3-(4,5-dimethylthiazol-2-YI)-2,5-diphenyltetrazolium bromide (MTT) assay}

After the transfection process, the cells were trypsinized. The cell suspension $\left(5 \times 10^{3}\right.$ cells/well $)$ in a 96-well plate was added with $20 \mu \mathrm{L}$ MTT solution (GD-Y1317, Guduo Biotechnology Company, Shanghai, China) per well at 24,48 and $72 \mathrm{~h}$ post transfection, respectively. The supernatant was aspirated after centrifugation, followed by the addition of $150 \mu \mathrm{L}$ dimethylsulfoxide (DMSO; D5879-100ML, Sigma-Aldrich, SF, CA) into each well. The optical density (OD) value was measured at $490 \mathrm{~nm}$ using a microplate reader (DG5031, Shanghai Bajiu Industrial Co., Ltd., Shanghai, China) [25]. Cell viability $=\left(\mathrm{OD}\right.$ value $\left.\mathrm{e}_{\text {experimental group }}-\mathrm{OD}_{\text {blank group }}\right) /\left(\mathrm{OD}_{\text {control }}\right.$ group $\left.-\mathrm{OD}_{\text {blank group }}\right) \times 100 \%$.

\section{Flow cytometry}

After transfection for $48 \mathrm{~h}$, the cells were fixed, centrifuged, and dyed with $500 \mu \mathrm{L}$ solution containing propidium iodide (PI, $50 \mu \mathrm{g} / \mathrm{mL}$ ) (88378, Sigma-Aldrich) and RNase A $(100 \mu \mathrm{g} / \mathrm{mL})$ (GE101-01, TransGen Biotech Co., Ltd., Beijing, China). A CytoFLEX flow cytometer (excitation wavelength: $488 \mathrm{~nm}$ ) was utilized to analyze the cell cycle.

Forty-eight $\mathrm{h}$ post transfection, the prepared Annexin-V/PI dying solution with Annexin-V-fluorescein isothiocyanate (FITC), propidium iodide (PI) and N-2-hydroxyethylpiperazine- $\mathrm{N}^{\prime}$-2-ethanesulfonic acid (HEPES) buffer (1:2:50) were incubated with cells together for $10 \mathrm{~min}$. The cells were probed with fluorescent solution SA-FLOUS (Origin Biosciences Inc., Nanjing, China) after centrifugation. To assess cell apoptosis, the fluorescence was detected using a $620-\mathrm{nm}$ bandpass filter for PI and a 525-nm bandpass filter for FITC at 488-nm excitation wavelength, respectively [26].

\section{Scratch test}

Uniform horizontal lines were drawn on the surface of the 6-well plates. Scratches perpendicular to the horizontal lines were subsequently made on the cell monolayers. Images were obtained at 0 and $24 \mathrm{~h}$ of incubation using an inverted microscope, and the cell migration distance between the scratches was measured accordingly [27].

\section{Transwell assay}

Transwell assay was conducted in a Transwell chamber by conventional means, with staining with crystal violet for $20 \mathrm{~min}$, whereupon the cells that had migrated through the Matrigel were counted in three randomly selecting fields from each sample [28].

\section{RNA immunoprecipitation (RIP)}

The binding between LINC00221 and Argonaute 2 (Ago2) protein as well as that between let-7a-5p and Ago2 was assessed using a RIP kit (Millipore Company, Billerica, MA). The cells were lysed by incubation in RIPA lysis buffer (P0013B, Beyotime Biotechnology) in an ice bath, followed by 10 -min centrifugation at $14,000 \mathrm{rpm}$ at $4{ }^{\circ} \mathrm{C}$. For each coprecipitation reaction system, $50 \mu \mathrm{L}$ magnetic beads were resuspended with $100 \mu \mathrm{L}$ RIP wash buffer, with addition of $5 \mu \mathrm{g}$ antibody: rabbit anti-Ago2 (1:100, ab32381, Abcam) or rabbit anti-human IgG (1:100, ab109489, Abcam) (used as NC). The obtained bead-antibody complex was then incubated overnight at $4{ }^{\circ} \mathrm{C}$ with cell lysate $(100 \mu \mathrm{L})$. One portion of the cell lysate was employed as the input. The samples and input were detached by protease $\mathrm{K}$ to extract RNA, followed by RT-qPCR.

\section{RNA pull-down}

Transfection was performed with the wild type (WT)biotinylated LINC00221 and mutant type (MUT)-biotinylated LINC00221 (50 nM for each) for $48 \mathrm{~h}$. Next, the cell lysate was reacted at $4{ }^{\circ} \mathrm{C}$ with $\mathrm{M}-280$ streptavidin magnetic beads (Sigma-Aldrich) that was precoated with RNase-free yeast tRNA (Sigma-Aldrich). $3 \mathrm{~h}$ later, the beads were rinsed. Finally, the expression of let-7a-5p in the eluted RNA was determined by RT-qPCR.

\section{Dual-luciferase reporter assay}

The cells $\left(2 \times 10^{5}\right.$ cells/well $)$ in 6 -well plates were transfected, and cultured for $48 \mathrm{~h}$. The luciferase activities of LINC00221 and MMP11 in the cells were 


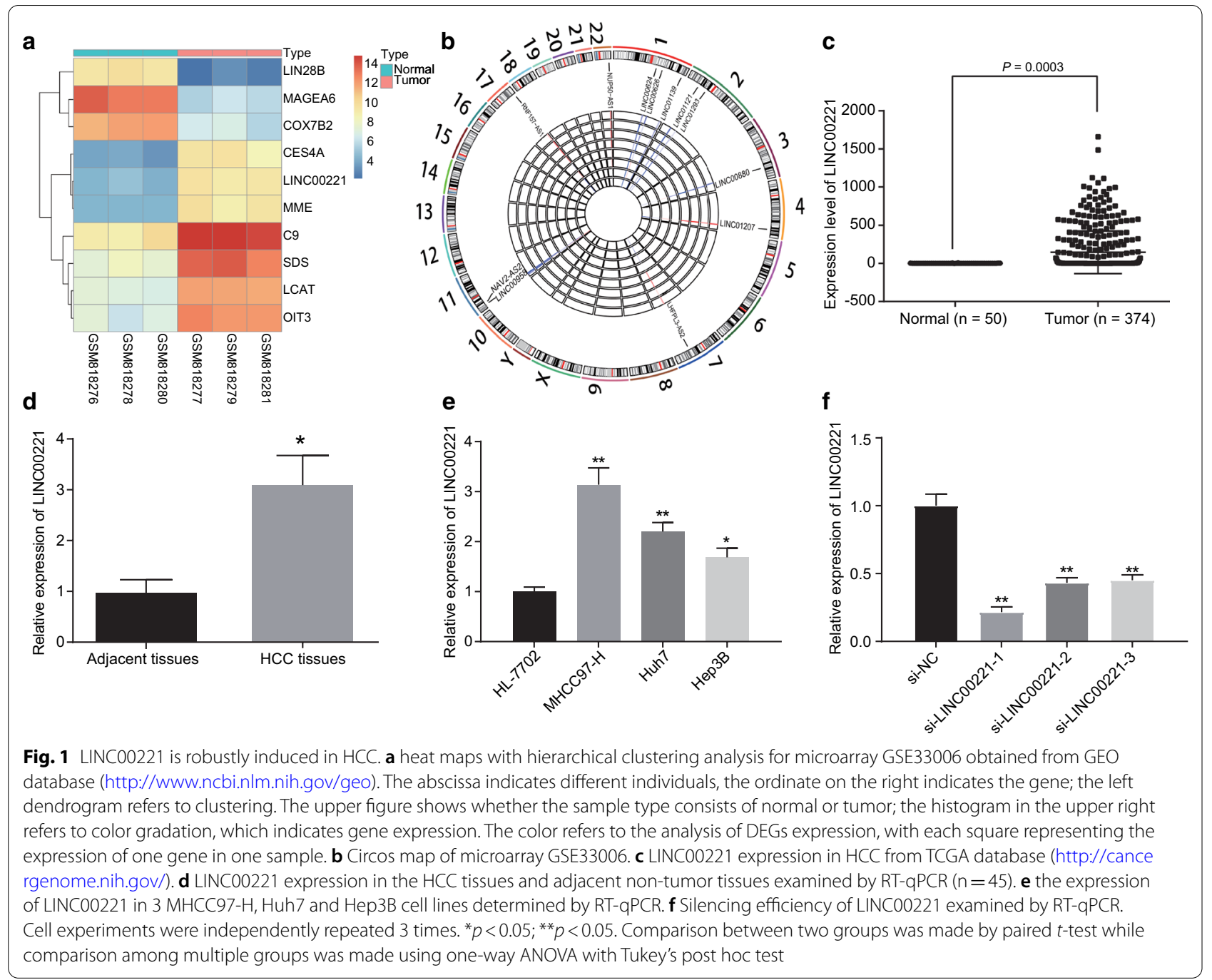

determined through application of the Genecopoeia dual-luciferase detection kit (D0010, Solarbio, Beijing, China). The luminance was detected using the Glomax20/20 luminometer provided by Promega (E5311, Zhongmei Biotechnology Co., Ltd., Shanxi, China).

\section{Animal treatment}

Forty-eight healthy nude mice (aged 6-8 weeks, weighing about 18-22 g) were purchased from the Department of Pharmacology, Institute of Materia Medica, Chinese Academy of Medical Sciences (Beijing, China). Mice were separately caged for 7 days in a specificpathogen-free animal laboratory with $60-65 \%$ humidity, $22-25^{\circ} \mathrm{C}$, and free access to feed and water, under a $12 \mathrm{~h}$ light/dark cycle. Mice were subcutaneously inoculated with $1 \times 10^{6}$ cells $/ \mu \mathrm{L}$ of cell suspension. Specifically, Huh7 and MHCC97-H cells $\left(2 \times 10^{5}\right.$ cells/ well) were seeded into a 6-well cell culture plate. Upon attaining $30 \%$ confluence, cells were infected with lentivirus $\left(2 \times 10^{6} \mathrm{TU}\right)$ expressing short hairpin RNA (sh)-NC, sh-LINC0022, oe-NC, or oe-LINC0022. The lentivirus was mixed with $5 \mu \mathrm{g}$ poly-brene, which was added into $1 \mathrm{~mL}$ serum-free and anti-bacterial medium. The infection efficiency was monitored under an inverted fluorescence microscope for 2-3 days. After $48 \mathrm{~h}$ of infection, puromycin $(1 \mu \mathrm{g} / \mathrm{mL})$ was added into each well to select stably infected cells. The cells were further cultured with complete medium after obtaining the stably infected cells. The tumor volume of each mouse was measured every seven days for five weeks, whereupon the mice were euthanized, and the tumor was removed and weighted. 
Table 3 The correlation of LINC00221 expression with the progression of HCC

\begin{tabular}{|c|c|c|c|}
\hline $\begin{array}{l}\text { Clinicopathological } \\
\text { characteristics }\end{array}$ & Case & LINC00221 expression & $p$ \\
\hline Age (years) & & & 0.689 \\
\hline$\leq 45$ & 16 & $3.076 \pm 0.714$ & \\
\hline$>45$ & 29 & $3.148 \pm 0.512$ & \\
\hline Gender & & & 0.824 \\
\hline Male & 26 & $3.139 \pm 0.540$ & \\
\hline Female & 19 & $3.099 \pm 0.654$ & \\
\hline Tumor size & & & 0.443 \\
\hline$\leq 5 \mathrm{~cm}$ & 17 & $3.035 \pm 0.631$ & \\
\hline$>5 \mathrm{~cm}$ & 28 & $3.175 \pm 0.560$ & \\
\hline Tumor number & & & 0.282 \\
\hline Single & 30 & $3.055 \pm 0.522$ & \\
\hline Multiple & 15 & $3.256 \pm 0.693$ & \\
\hline Clinical grade & & & 0.001 \\
\hline$|/| \mid$ & 21 & $2.822 \pm 0.704$ & \\
\hline III & 24 & $3.385 \pm 0.262$ & \\
\hline TNM stage & & & 0.005 \\
\hline$|/| \mid$ & 28 & $2.936 \pm 0.639$ & \\
\hline III & 17 & $3.429 \pm 0.300$ & \\
\hline LNM & & & 0.001 \\
\hline Yes & 11 & $3.517 \pm 0.593$ & \\
\hline No & 34 & $2.994 \pm 0.336$ & \\
\hline $\operatorname{AFP}(\mathrm{ng} / \mathrm{mL})$ & & & $<0.001$ \\
\hline$\leq 200$ & 21 & $2.824 \pm 0.706$ & \\
\hline$>200$ & 24 & $3.383 \pm 0.262$ & \\
\hline
\end{tabular}

HCC hepatocellular carcinoma, TNM tumor node metastasis, LNM lymph node metastasis, AFP alpha-fetoprotein

\section{Statistical analysis}

SPSS 21.0 software (IBM Corp., Armonk, NY) was utilized for data analysis $(p<0.05$ was defined as statistically significant). Measurement data were expressed as mean \pm standard deviation. All experiments were independently conducted three times, and all data were evaluated for normality and homogeneity of variance. Comparison between cancerous and adjacent non-cancerous tissues was made using paired $t$-test while that between other two groups was performed by unpaired $t$-test. Multiple groups were compared by one-way analysis of variance (ANOVA) with Tukey's post hoc test. The repeated measures ANOVA was performed for the comparison of tumor volume at different time points, whereas two-way ANOVA was conducted for comparing cell viability at indicated time points, followed by Bonferroni post hoc test.

\section{Results}

\section{LINC00221 is highly expressed in HCC}

Microarray analysis (GSE33006) revealed an upregulation of LINC00221 in HCC (Fig. 1a-c). Analysis by RT-qPCR demonstrated noticeably higher expression of LINC00221 in the HCC tissues versus adjacent nontumor tissues (Fig. 1d). LINC00221 expression in three HCC cell lines (MHCC97-H, Huh7, and Hep3B) was measured by RT-qPCR. Consistently, higher LINC00221 expression was observed in Huh7 and MHCC97-H cell lines than in HL-7702, so these two cell lines were selected for subsequent cell experiments (Fig. 1e). After cell transfection, si-LINC00221-1, si-LINC00221-2 and si-LINC00221-3 decreased the LINC00221 expression, among which the si-LINC00221-1 treatment exhibited the best silencing efficiency (Fig. 1f). Therefore, the siLINC00221-1 was selected for the LINC00221 loss-offunction experiments.

After correlation analysis, we determined that LINC00221 expression was highly correlated to lymph node metastasis (LNM), clinical grade, TNM staging, and AFP content (Table 3). Patients at stage IIIa HCC exhibited a lower positive expression of LINC00221 (37.78\%) than that those at stage I/II HCC (62.22\%). The positive expression of LINC00221 in grade I//II patients (46.67\%) was lower than that in patients at grade III (53.33\%). Positive expression of LINC00221 in patients with LNM $(24.44 \%)$ was lower than that in patients without LNM (75.56\%), while the positive expression of LINC00221 in patients with an AFP greater than $200 \mathrm{ng} / \mathrm{mL}$ (53.33\%) was higher than those with an AFP less than or equal to $200 \mathrm{ng} / \mathrm{mL}$ (46.67\%). However, LINC00221 expression displayed no marked difference in terms of gender, age, or tumor volume and number.

\section{Repression of LINC00221 inhibits proliferation and enhances apoptosis of HCC Cells}

As depicted in Fig. 2a, the results of the MTT assay revealed no significant difference at the $24^{\text {th }} \mathrm{h}$ post transfection between the Huh7 and MHCC97-H cells. Cell viability was notably lowered by si-LINC00221 but enhanced by oe-LINC00221 in both cell lines. Additionally, as revealed by the PI single staining results (Fig. 2b, c, Additional file 1: Figure S1A, B), there was no significant difference concerning cell cycle in either cell line among blank, si-NC and oe-NC groups. si-LINC00221 treatment resulted in an elevated proportion of the cells at the G1 phase, but a reduced proportion of the cells at the $S$ phase, while oe-LINC00221 led to enhanced cell cycle entry both in Huh7 and MHCC97-H cells. Annexin V/ 


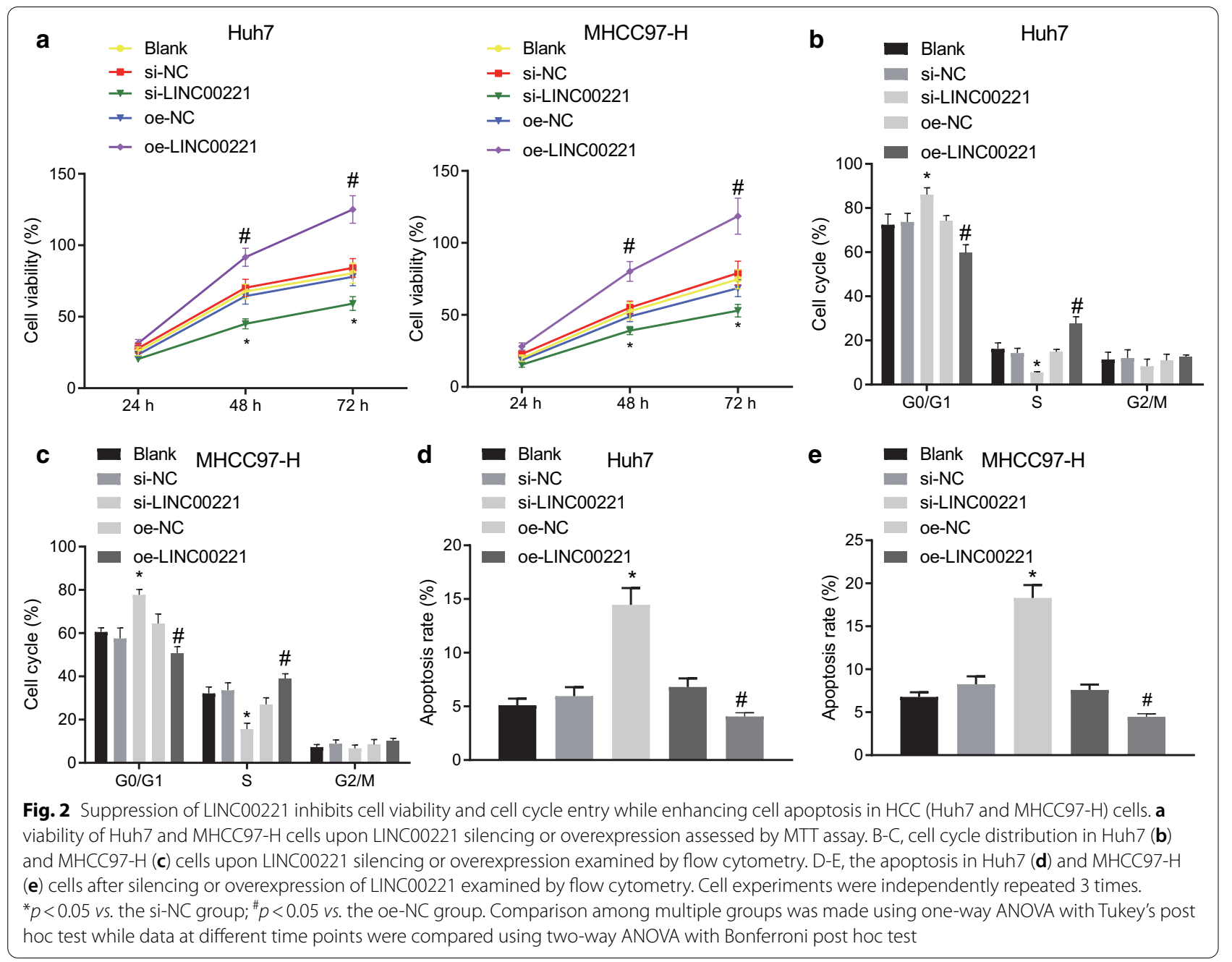

PI double staining results displayed no significant difference among the blank, si-NC and oe-NC groups in either cell line. However, their apoptosis rates were elevated by si-LINC00221 but reduced by oe-LINC00221 treatment (Fig. 2d, e, Additional file 1: Figure S1C, D). Therefore, silencing LINC00221 could inhibit cancer progression in HCC cells.

\section{Repression of LINC00221 reduces the migration and invasion of HCC cells}

As revealed by the data from Scratch test and Transwell assay, the Huh7 and MHCC97-H cells exhibited consistent changes following alternations of their LINC00221 expression. As illustrated in Fig. 3a, b, Additional file 2: Figure S2A, B, Fig. 3c, d, and Additional file 2: Figure S2C, D, si-LINC00221 induced significantly decreased cell migration distance and fewer invasive cells, while oeLINC00221 caused enhanced cell migration and invasion.

The expression patterns of anti-apoptotic protein Bcl-2, pro-apoptotic protein Bax, and cell cycle markers cyclin
D1 and CDK4 in Huh7 cells and MHCC97-H cells were measured by immunoblotting. The expression of $\mathrm{Bcl}-2$, cyclin D1 and CDK4 was significantly decreased, while that of Bax was increased upon si-LINC00221 treatment. However, the expression of Bcl-2, cyclin D1 and CDK4 was enhanced, while Bax expression was reduced in response to oe-LINC00221 treatment (Fig. 3e, f). Taken together, the above findings led us to conclude that silencing LINC00221 suppressed the migrating and invading properties of HCC cells.

\section{Inhibition of LINC00221 suppresses tumor growth in HCC}

We further investigated whether LINC00221 could function in vivo. LINC00221-deficient or LINC00221-overexpressed Huh7/MHCC97-H cells were transplanted into HCC nude mice. The expression of LINC00221 was markedly reduced in the tumor xenografts of nude mice transplanted with LINC00221-deficient Huh7/MHCC97$\mathrm{H}$ cells, while its expression was considerably elevated in the tumor xenografts of mice transplanted with Huh7/ 
MHCC97-H cells overexpressing LINC00221 (Additional file 3: Figure S3). The volume and weight of transplanted tumors were significantly reduced by LINC00221 knockdown, yet the volume and weight of transplanted tumors were notably elevated upon enhanced LINC00221 expression (Fig. 4a-c). These findings suggested that silencing of LINC00221 was capable of suppressing tumor growth in vivo.

\section{LINC00221 upregulates the expression of MMP11 by competitively binding to Let-7a-5p}

Analysis of an IncRNA subcellular localization website (http://lncatlas.crg.eu/) [29] revealed that LINC00221 was predominately located in the cytoplasm (Fig. 5a). Through the application of FISH, as shown in Fig. 5b, the green-stained LINC00221 probe was mainly located in the cytoplasm, while the nucleus was stained in blue. In merged images, green fluorescence was clearly observed in the cytoplasm, indicative of the localization of LINC00221 in the cytoplasm.

The downstream regulatory miRNAs predicted by the RNA22 database were intersected with the downregulated miRNAs in HCC samples from the GSE12717 microarray. Only let-7a-5p was present at the intersection (Fig. 5c). We also observed a specific binding site between LINC00221 and let-7a-5p sequences (Fig. 5d). To explore further the downstream mechanism of this interaction, we employed Starbase, mirDIP and miRDB databases to predict the targets of let-7a-5p. By intersecting those target genes with upregulated genes in HCC samples from GSE89377 and GSE117361 microarrays, we identified MMP11, COL1A1 and COL1A2 (Fig. 5e), among which MMP11 has rarely been reported in previous studies on HCC. Moreover, we found a specific binding site between let-7a-5p and the MMP11 sequence (Fig. 5f). The above results suggested that LINC00221 might regulate MMP11 expression via binding to let-7a-5p. To validate this, we then applied a luciferase assay. Results of this assay (Fig. 5e) demonstrated that the luciferase activity of pGL3-LINC00221 or pGL3-MMP11-3'UTR was decreased by co-transfection with let-7a-5p mimic, while that of pGL3-MMP11-3'UTR was also decreased after co-transfection with si-LINC00221. Then, we found that the HCC tissues displayed markedly decreased let-7a-5p expression levels accompanied by elevated MMP11 protein expression relative to adjacent non-tumor tissues (Fig. 5f, g). The application of a RIP assay revealed that, in contrast to the IgG group, the Ago2 group had significantly higher levels of LINC00221 and let-7a-5p expression (Fig. 5h). The application of an RNA pull-down exhibited that, compared with the Bio-LINC00221-MUT group, the Bio-LINC00221-WT group exhibited significantly increased let-7a-5p expression (Fig. 5i). After inhibition of LINC00221, the level of let-7a-5p expression markedly decreased (Fig. 5 j), while MMP11 protein expression was conspicuously decreased upon let-7a-5p mimic transfection $(p<0.05)$ (Fig. $5 \mathrm{k})$. Taken then above, we concluded that LINC00221 upregulated the MMP11 expression by competitively binding to let-7a-5p.

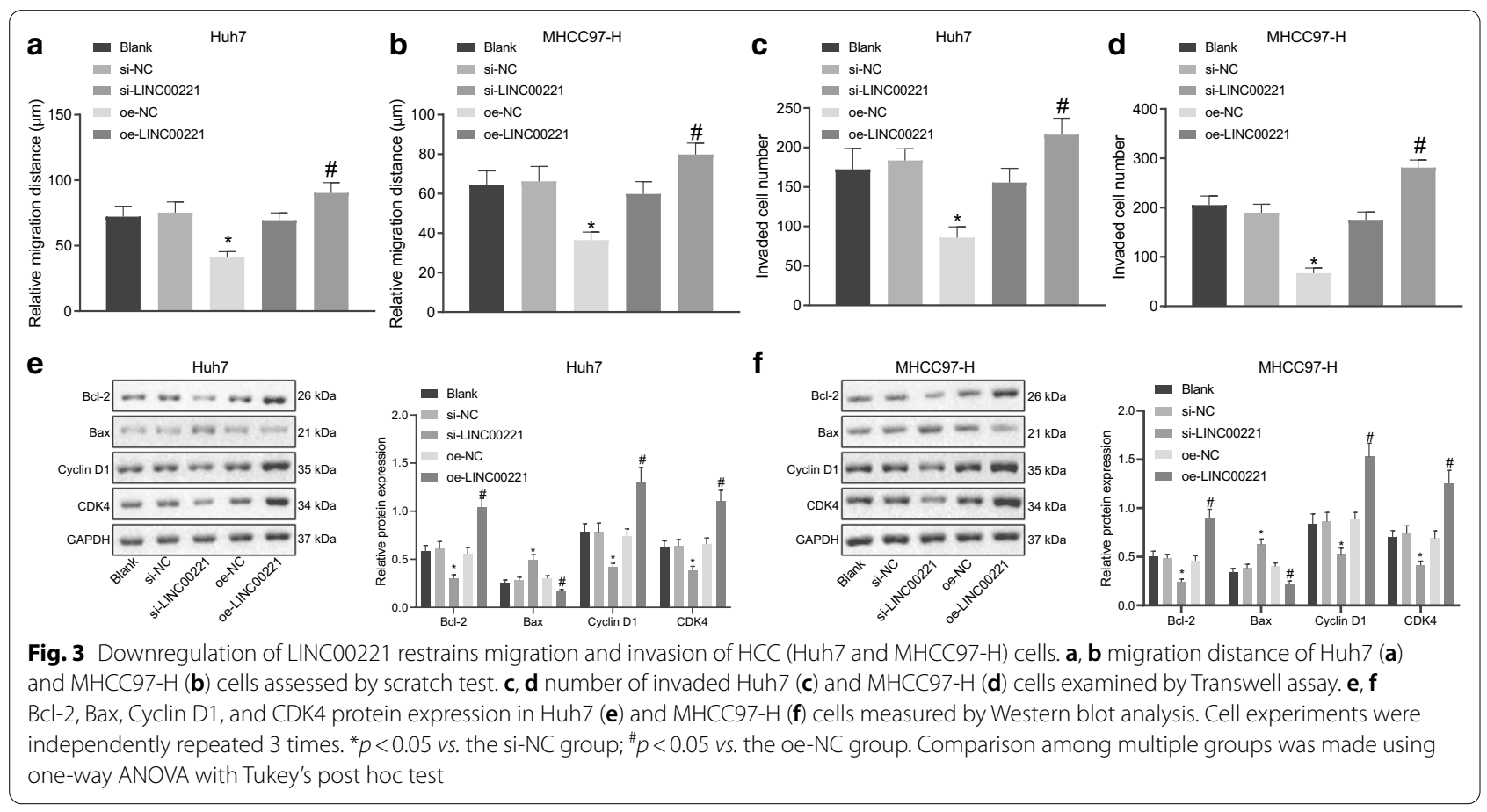



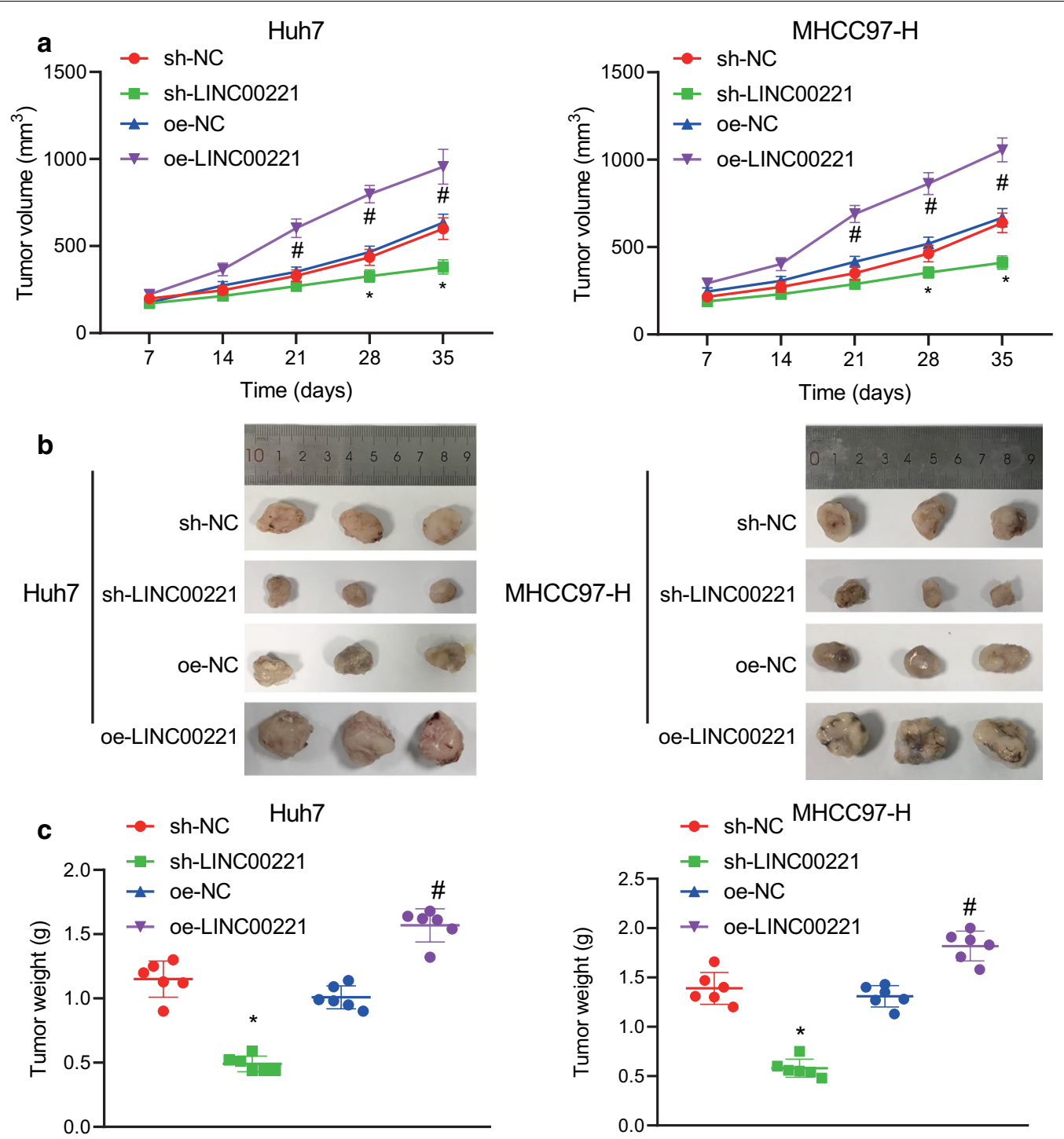

Fig. 4 Suppression of LINC00221 inhibits tumor growth in vivo. a Tumor volume in nude mice; $\mathbf{b}$ Representatives images of transplanted tumors formed in nude mice; $\mathbf{c}$ Tumor weight. $N=6 .{ }^{*} p<0.05$ vs. the sh-NC group; ${ }^{*} p<0.05$ vs. the oe-NC group. Comparison among multiple groups was made using one-way ANOVA with Tukey's post hoc test while data at different time points were compared using repeated measures ANOVA with Bonferroni post hoc test

Knock-down of LINC00221 represses the aggressiveness but enhances apoptosis of HCC cells by inhibiting MMP11 via upregulation of Let-7a-5p

Huh7 cells and MHCC97-H cells were transfected with let-7a-5p mimic to explore its effect on the progression of HCC. In particular, we conducted transfection with si-LINC00221 + si-MMP11 or with si-LINC00221 + oeMMP11 to analyze whether LINC00221 participated in the growth of $\mathrm{HCC}$ by regulating the let-7a $-5 \mathrm{p} / \mathrm{MMP} 11$ axis. Results showed that let-7a-5p mimic treatment obviously decreased the MMP11 protein expression. MMP11 protein expression was appreciably lowered by si-MMP11, but rescued by oe-MMP11 treatment in the LINC00221-deficient cells (Fig. 6a). The MTT assay results as displayed in Fig. $6 \mathrm{~b}$ revealed that cell proliferation was significantly diminished by let-7a-5p mimic, while a similar decrease was induced by si-MMP11 in the LINC00221-deficient cells. However, cell proliferation suppressed by si-LINC00221 was rescued by oeMMP11. The flow cytometric data in Fig. 6c displayed that let-7a-5p mimic provoked significantly higher cell apoptosis, and that si-MMP11 induced an enhancement of cell apoptosis in LINC00221-deficient cells. On the other hand, cell apoptosis induced by si-LINC00221 


\begin{abstract}
(See figure on next page.)
Fig. 5 LINC00221 upregulates the MMP11 expression by competitively binding to let-7a-5p. a LncATLAS website for IncRNA subcellular localization revealed that LINC00221 was mainly located in the cytoplasm. b The subcellular localization of LINC00221 verified by FISH assay $(\times 400$; the left) and the co-localization profile intensity (the right). c Venn map (http://bioinformatics.psb.ugent.be/webtools/Venn/) showing downstream regulatory miRNAs of LINC00221 predicted by RNA22 database (https://cm.jefferson.edu/rna22/Precomputed/) (blue circle) and downregulated miRNAs in HCC samples from GSE12717 microarray (red circle). d The binding site between LINC00221 and let-7a-5p sequences predicted on the RNA22 website. e Venn map showing downstream target genes of let-7a-5p predicted by Starbase (http://starbase.sysu.edu.cn/index.php) (blue circle), mirDIP (http://ophid.utoronto.ca/mirDIP/) (red circle), and miRDB (http://www.mirdb.org/) (green circle), and upregulated genes in HCC samples from GSE89377 microarray (yellow circle) and from GSE117361 microarray (orange circle). f The binding site between let-7a-5p and MMP11 predicted on the RNA22 website. $\mathbf{g}$ The relationships among LINC00221, let-7a-5p and MMP11 identified by dual-luciferase reporter gene assay. $\mathbf{h}$ The let-7a-5p expression in HCC and adjacent non-tumor tissues $(n=45)$ examined by RT-qPCR. $\mathbf{i}$ The MMP11 protein expression in HCC and adjacent non-tumor tissues $(n=45)$ measured by Western blot analysis. $\mathbf{j}$ The relationships among LINC00221, let-7a-5p and Ago2 determined by RIP assay. $\mathbf{k}$ The binding of LINC00221 to let-7a-5p identified by RNA pull-down. I The regulatory effect of LINC00221 on let-7a-5p expression examined by RT-qPCR. $\mathbf{m}$ MMP11 protein expression after upregulation of let-7a-5p measured by western blot analysis. Cell experiments were independently repeated 3 times. ${ }^{*} p<0.05$ vs. the mimic NC group, si-NC group or adjacent non-tumor tissues $(n=45)$; ${ }^{\circledR} p<0.05$ vs. the lgG group; ${ }^{*} p<0.05$ vs. the Bio-LINC00221-MUT group. Comparison between HCC and adjacent non-tumor tissues was made using paired $t$-test while comparison between other two groups was performed by unpaired t-test
\end{abstract}

was decreased by oe-MMP11. Furthermore, the Transwell assay revealed that cell invasion was markedly decreased by the let-7a-5p mimic treatment, with a similar reduction identified in the LINC00221-deficient cells upon MMP11 knockdown. Moreover, cell invasion suppressed by si-LINC00221 was enhanced by oeMMP11 (Fig. 6d).

At the molecular level, the expression of $\mathrm{Bcl}-2$, Cyclin D1 and CDK4 proteins was decreased, but Bax protein expression was upregulated by let-7a-5p mimic. In contrast to the si-LINC00221 + si-NC group, we observed reduced expression of $\mathrm{Bcl}-2$, cyclin $\mathrm{D} 1$ and CDK4 proteins in the si-LINC00221+si-MMP11 group, accompanied with elevated expression of Bax protein. Conversely, oe-MMP11 could partially reverse the changes in expression of the aforementioned proteins caused by si-LINC00221 (Fig. 6e).

The Huh7 and MHCC97-H cells exhibited similar changes regarding the aforementioned cellular behaviors and molecular levels. Taken together, the results indicated that LINC00221 silencing inhibited MMP11 by upregulating let-7a-5p, thus limiting the malignancy of HCC cells.

\section{Discussion}

In the progression of $\mathrm{HCC}$, various genetic and epigenetic alterations regulate the function of proteins post-translationally, which in turn facilitate invasion and metastasis [30]. The present study elucidated the mechanisms associated with the regulatory effects of LINC00221 on HCC cellular behaviors. Our results suggested that LINC00221 promoted the progression of $\mathrm{HCC}$ via a mediation of the let-7a-5p/MMP11 axis (Fig. 7).

Aberrant expressions of lncRNAs are known for their contribution to hepatocarcinogenesis [31]. Our initial findings in this study revealed that LINC00221 was aberrantly increased in HCC tissues, and that this aberrant increase correlated with advanced LNM, clinical grade and TNM stage of HCC. However, LINC00221 silencing could impede the proliferative, invasive and oncogenic potentials of HCC cells and enhance their apoptosis. It is well-known that lncRNAs can sometimes act as ceRNAs, thus modulating the expression of different miRNAs in a cell-type dependent manner [32]. LINC00221, which is also involved in the ceRNA network in HCC [10], was further observed in this study to act as a ceRNA of let-7a-5p. Existing literature has indicated that let-7a has low expression in HCC cells [33], whereas let-7a overexpression suppresses growth, invasion, and sphere formation capability of HCC stem-like cells [34]. These literature results are partially consistent with our present findings that upregulating let-7a-5p could enhance malignant functions of HCC cells. Similarly, let$7 a-5 p$ expression is downregulated in lung cancer, and its decreased expression is conductive to the progression of this cancer [35].

Furthermore, the binding of miRNAs to lncRNAs decreased miRNA levels and led to increased expression of miRNA target genes [36]. The new evidence provided by our study also supported the notion that LINC00221 overexpression resulted in increased MMP11 levels by competitively binding to let-7a-5p. Previous data have suggested that LINC00221 sponges miR-519a to mediate the expression of ZBTB5, which is a mechanism involved in the regulation of cisplatin resistance in non-small-cell lung cancer (NSCLC) [37]. Another let-7 family member, let-7c, targets MMP11 to suppress metastasis in colorectal cancer [38]. Liu et al. have demonstrated that lncRNA nuclear paraspeckle assembly transcript 1 (NEAT1) negatively interacts with let-7a-5p to increase the expression of the let-7a-5p target gene Rsf-1 in NPC [39]. MMP11 has been proposed to be a hub cancer driver gene in 


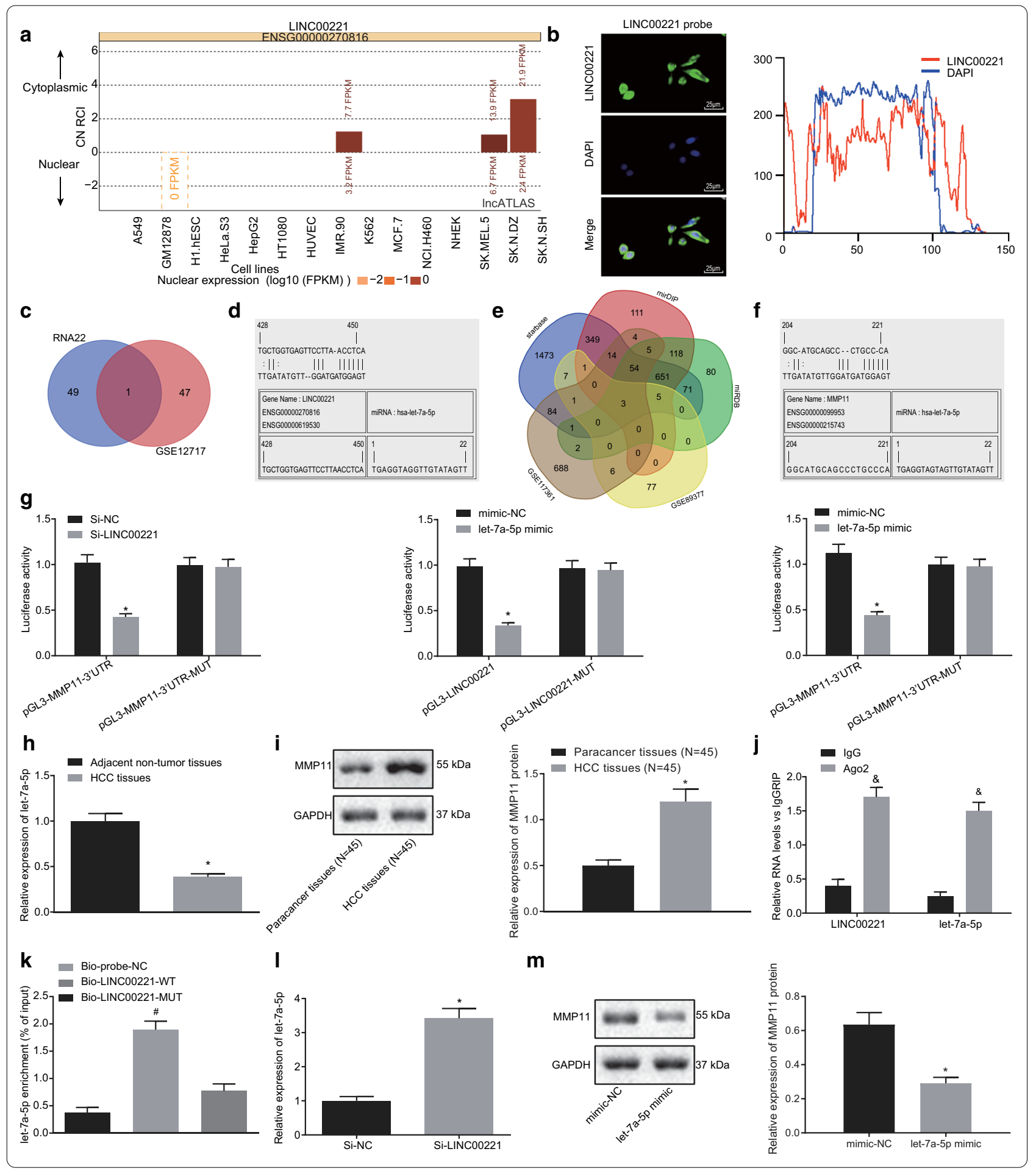

lung adenocarcinoma [40]. Our present findings demonstrated that MMP11 exerted tumor-promotive functions on the progression of HCC. Indeed, a large number of previous studies have shown that MMP11 functions as an oncogene in a variety of cancers. For example, inhibition of MMP11 can impede the metastasis of gastric cancer [41]. Likewise, a previous study has shown that knockdown of MMP11 can hamper cancer progression in lung adenocarcinoma cells as well as impeding tumor growth in xenograft models [42]. More importantly, genetic 


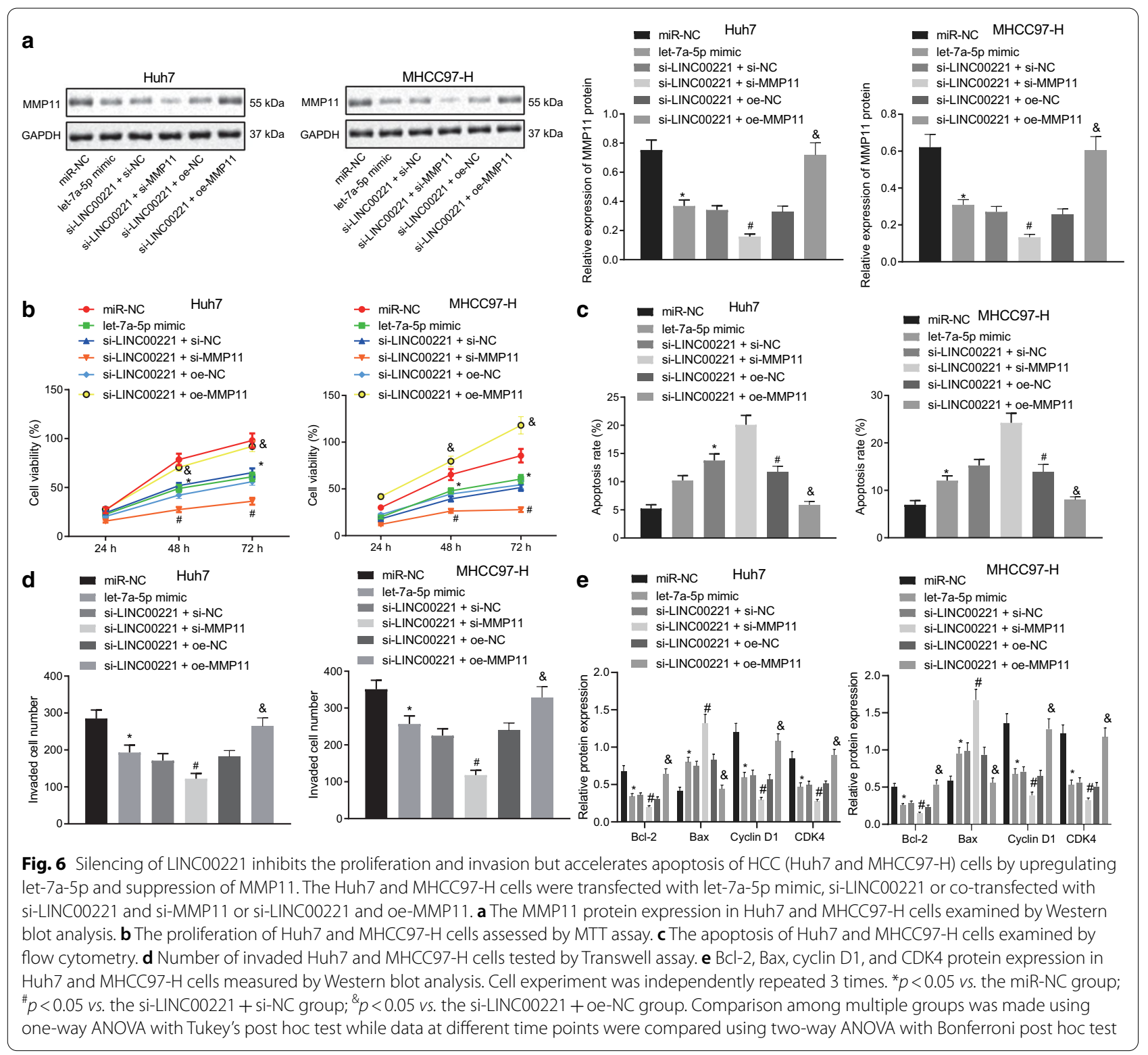

variations in MMP11 may function as a reliable biomarker for the progression of HCC [43], while another study has reported that MMP11 contributes to HCC proliferation and metastasis by acting as the target gene of miR-125a [18]. In this study, we demonstrated that LINC00221 silencing suppressed the in vitro progression of HCC via upregulation of let-7a-5p and inhibition of MMP11 expression. Similarly, suppression of LINC01561 can inhibit cancer cell proliferation and facilitate apoptosis in breast cancer via increasing expression of miR145-5p as well as reducing expression of MMP11 [17]. Additionally, overexpressing of lncRNA LOXL1-AS1 can accelerate cell proliferating and migrating processes, but restrain apoptosis via upregulating EGFR expression though inhibition of let-7a-5p [44]. Wang et al. have demonstrated that lncRNA antisense non-coding RNA in the INK4 locus (ANRIL) knockdown inhibits the tumorigenicity of NPC cells by modulating let-7a [45].

\section{Conclusion}

We have elucidated the potential role of LINC00221 in $\mathrm{HCC}$ and provided new evidence that the silencing of LINC00221 contributed to prevention of HCC progression via let-7a-5p-targeted inhibition of MMP11. The demonstration of this mechanistic axis may provide novel insights for developing new targets for 


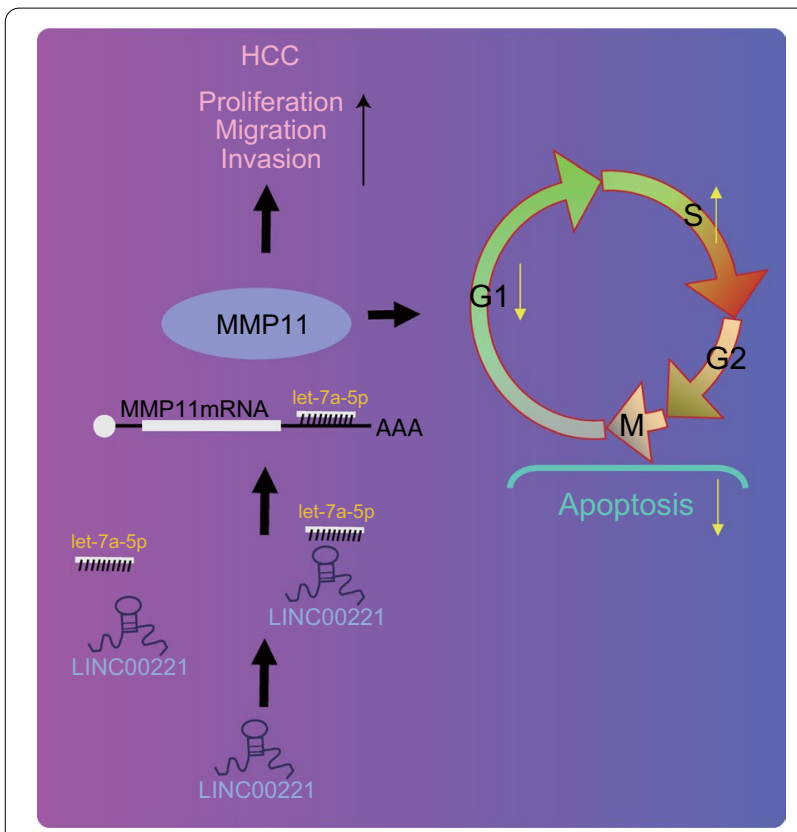

Fig. 7 The mechanism involved LINC00221 in regulating the progression of HCC. LINC00221 was upregulated while let-7a-5p was downregulated in HCC cells, and highly expressed LINC00221 upregulated MMP11 expression by competitively binding to let-7a-5p, thereby promoting HCC cell viability, migration, and restraining cell apoptosis

the improved treatment of HCC. Present results are encouraging for further investigations with larger sample size and with consideration of the confounding effects of targeted therapy with chemotherapy or chemoresistance on HCC.

\section{Abbreviations}

HCC: Hepatocellular carcinoma; IncRNAs: Long non-coding RNAs; TCGA: The Cancer Genome Atlas; GEO: Gene Expression Omnibus; ceRNA: Competitive endogenous RNA; miRNAs: MicroRNAs; RSU1P2: Ras suppressor protein 1 pseudogene 2; MMP11: Matrix metalloproteinase 11; FDR: False positive discovery; DEGs: Differentially expressed genes; TNM: Tumor-Node-Metastasis; mUICC: Modified Union for International Cancer Control; AFP: Alpha-fetoprotein; FISH: Fluorescence in situ hybridization; NC: Negative control; RT-qPCR: Reverse transcription quantitative polymerase chain reaction; GAPDH: Glyceraldehyde-3-phosphate dehydrogenase; OD: Optical density; RIP: RNA Immunoprecipitation; WT: Wild type; MUT: Mutant type; LNM: Lymph node metastasis; NSCLC: Non-small-cell lung cancer; NEAT1: Nuclear paraspeckle assembly transcript 1

\section{Supplementary Information}

The online version contains supplementary material available at https://doi. org/10.1186/s12935-021-01819-w.

Additional file 1: Figure S1. Suppression of LINC00221 inhibits cell cycle entry while enhancing cell apoptosis in Huh7 and MHCC97-H cells. A-B, Representative images showing cell cycle in Huh7 (A) and MHCC97-H (B) cells upon LINC00221 silencing or overexpression examined by flow cytometry. C-D, Representative flow cytometric dot plots apoptosis in
Huh7 (C) and MHCC97-H (D) cells after silencing or overexpression of LINC00221.

Additional file 2: Figure S2. Downregulation of LINC00221 restrains migration and invasion of HCC (Huh7 and MHCC97-H) cells. A-B, Representative images of migration distance of Huh7 (A) and MHCC97-H (B) cells assessed by scratch test. C-D, Representative images of invaded Huh7 (C) and MHCC97-H (D) cells examined by Transwell assay.

Additional file 3: Figure S3. Expression of LINC00221 in the tumor xenografts of nude mice transplanted with Huh7/MHCC97-H cells.

\section{Acknowledgements}

We acknowledge and appreciate our colleagues for their valuable efforts and comments on this paper.

\section{Authors' contributions}

$L Y, H L S, M M, Y F$ and YNJ wrote the paper and conceived and designed the experiments; LY, HLS, MM, YF, JTW, HJX and CZ analyzed the data; JTW, CZ and HJX collected and provided the sample for this study. All authors read and approved the final manuscript.

\section{Funding}

This study was supported by Natural Science Foundation Youth Project of Shaanxi Province (No. 2018JQ8014); Subject Innovation Team of Shaanxi University of Chinese Medicine (2019-YL06) and National Natural Science Foundation Youth Project of China (No. 81704066).

\section{Availability of data and material}

The datasets generated/analyzed during the current study are available.

\section{Ethics approval and consent to participate}

Written informed consents were signed by all participating patients. The experiments for human tissue samples were approved by Ethic Committee of Affiliated Hospital of the Shaanxi University of Traditional Chinese Medicine and performed in line with the Declaration of Helsinki. The experiments involved animals were conducted in compliance with the Guide for for the Care and Use of Laboratory Animals issued by National Institute of Health. Great efforts were made to minimize the number and suffering of animals.

\section{Consent for publication}

Consent for publication was obtained from the participants.

\section{Competing interests}

The authors have declared that no competing interests exist.

\section{Author details}

1 Department of Hepatobiliary Surgery, Shaanxi Province, Xianyang Central Hospital, No. 78, Renmin East Road, Weicheng District, Xianyang 712000,

People's Republic of China. ${ }^{2}$ Department of Oncology, Shaanxi Province, Affiliated Hospital of the Shaanxi University of Traditional Chinese Medicine, No. 2, Weiyang West Road, Xianyang 712000, People's Republic of China. ${ }^{3}$ Diagnostic Teaching and Research Unit, Shaanxi University of Traditional Chinese Medicine, Xianyang 712046, People's Republic of China.

Received: 14 May 2020 Accepted: 6 February 2021

Published online: 09 April 2021

\section{References}

1. Zhang Z, Chen C, Guo W, Zheng S, Sun Z, Geng X. DNM3 attenuates hepatocellular carcinoma growth by activating P53. Med Sci Monit. 2016;22:197-205.

2. Chen $Y L$, Xu QP, Guo F, Guan WH. MicroRNA-302d downregulates TGFBR2 expression and promotes hepatocellular carcinoma growth and invasion. Exp Ther Med. 2017;13(2):681-7. 
3. Ringelhan M, Pfister D, O'Connor T, Pikarsky E, Heikenwalder M. The immunology of hepatocellular carcinoma. Nat Immunol. 2018;19(3):222-32.

4. Godoy P, Bolt HM. Hepatocellular cancer. Arch Toxicol. 2013;87(2):225-6.

5. Xu J, Wu C, Che X, Wang L, Yu D, Zhang T, Huang L, Li H, Tan W, Wang C, et al. Circulating microRNAs, miR-21, miR-122, and miR-223, in patients with hepatocellular carcinoma or chronic hepatitis. Mol Carcinog. 2011;50(2):136-42.

6. Calderaro J, Rousseau B, Amaddeo G, Mercey M, Charpy C, Costentin C, Luciani A, Zafrani ES, Laurent A, Azoulay D, et al. Programmed death ligand 1 expression in hepatocellular carcinoma: relationship with clinical and pathological features. Hepatology. 2016;64(6):2038-46.

7. Fang TT, Sun XJ, Chen J, Zhao Y, Sun RX, Ren N, Liu BB. Long noncoding RNAs are differentially expressed in hepatocellular carcinoma cell lines with differing metastatic potential. Asian Pac J Cancer Prev. 2014;15(23):10513-24.

8. Yang J, Lin J, Liu T, Chen T, Pan S, Huang W, Li S. Analysis of IncRNA expression profiles in non-small cell lung cancers (NSCLC) and their clinical subtypes. Lung Cancer. 2014;85(2):110-5.

9. Simo-Riudalbas L, Diaz-Lagares A, Gatto S, Gagliardi M, Crujeiras AB, Matarazzo MR, Esteller M, Sandoval J. Genome-wide DNA methylation analysis identifies novel hypomethylated non-pericentromeric genes with potential clinical implications in ICF syndrome. PLoS ONE. 2015;10(7):e0132517.

10. Long J, Bai Y, Yang X, Lin J, Yang X, Wang D, He L, Zheng Y, Zhao H. Construction and comprehensive analysis of a ceRNA network to reveal potential prognostic biomarkers for hepatocellular carcinoma. Cancer Cell Int. 2019:19:90.

11. Ye B, Hu B, Zheng Z, Zheng R, Shi Y. The long non-coding RNA AK023948 enhances tumor progression in hepatocellular carcinoma. Exp Ther Med. 2017;14(4):3658-64.

12. Mao TL, Fan KF, Liu CL. Targeting the CXCR4/CXCL12 axis in treating epithelial ovarian cancer. Gene Ther. 2017;24(10):621-9.

13. Zhang PF, Li KS, Shen YH, Gao PT, Dong ZR, Cai JB, Zhang C, Huang XY, Tian MX, Hu ZQ, et al. Galectin-1 induces hepatocellular carcinoma EMT and sorafenib resistance by activating FAK/PI3K/AKT signaling. Cell Death Dis. 2016;7:e2201.

14. Shi DM, Bian XY, Qin CD, Wu WZ. miR-106b-5p promotes stem cell-like properties of hepatocellular carcinoma cells by targeting PTEN via PI3K/ Akt pathway. Onco Targets Ther. 2018;11:571-85.

15. Tay Y, Rinn J, Pandolfi PP. The multilayered complexity of ceRNA crosstalk and competition. Nature. 2014;505(7483):344-52.

16. Liu Q, Guo X, Que S, Yang X, Fan H, Liu M, Li X, Tang H. LncRNA RSU1P2 contributes to tumorigenesis by acting as a ceRNA against let-7a in cervical cancer cells. Oncotarget. 2017;8(27):43768-81.

17. Jiang R, Zhao C, Gao B, Xu J, Song W, Shi P. Mixomics analysis of breast cancer: Long non-coding RNA linc01561 acts as ceRNA involved in the progression of breast cancer. Int J Biochem Cell Biol. 2018;102:1-9.

18. Bi Q, Tang S, Xia L, Du R, Fan R, Gao L, Jin J, Liang S, Chen Z, Xu G, et al. Ectopic expression of MiR-125a inhibits the proliferation and metastasis of hepatocellular carcinoma by targeting MMP11 and VEGF. PLOS ONE. 2012;7(6):e40169.

19. Fujita A, Sato JR, Rodrigues Lde O, Ferreira CE, Sogayar MC. Evaluating different methods of microarray data normalization. BMC Bioinformatics. 2006;7:469.

20. Smyth GK. Linear models and empirical bayes methods for assessing differential expression in microarray experiments. Stat Appl Genet Mol Biol. 2004;3:Article3.

21. Robinson MD, McCarthy DJ, Smyth GK. edgeR: a Bioconductor package for differential expression analysis of digital gene expression data. Bioinformatics. 2010;26(1):139-40.

22. Zhou L, Rui JA, Zhou WX, Wang SB, Chen SG, Qu Q. EdmondsonSteiner grade: a crucial predictor of recurrence and survival in hepatocellular carcinoma without microvascular invasio. Pathol Res Pract. 2017;213(7):824-30.

23. Kim TH, Park JW, Kim BH, Kim H, Moon SH, Kim SS, Woo SM, Koh YH, Lee WJ, Kim DY, et al. Does risk-adapted proton beam therapy have a role as a complementary or alternative therapeutic option for hepatocellular carcinoma? Cancers. 2019;11(2):230.
24. Lee JC, Cheng CH, Wang YC, Wu TH, Lee CF, Wu TJ, Chou HS, Chan KM, Lee WC. Clinical relevance of alpha-fetoprotein in determining resection margin for hepatocellular carcinoma. Medicine. 2019;98(11):e14827.

25. Jensen NK, Mulder D, Lock M, Fisher B, Zener R, Beech B, Kozak R, Chen J, Lee TY, Wong E. Dynamic contrast enhanced CT aiding gross tumor volume delineation of liver tumors: an interobserver variability study. Radiother Oncol. 2014;111(1):153-7.

26. Montasser MF, Abdelkader NA, Abdelhakam SM, Dabbous H, Montasser IF, Massoud YM, Abdelmoaty W, Saleh SA, Bahaa M, Said H, et al. Bacterial infections post-living-donor liver transplantation in Egyptian hepatitis C virus-cirrhotic patients: a single-center study. World J Hepatol. 2017:9(20):896-904.

27. Xu JH, Chang WH, Fu HW, Shu WQ, Yuan T, Chen P. Upregulated long non-coding RNA LOC90784 promotes cell proliferation and invasion and is associated with poor clinical features in HCC. Biochem Biophys Res Commun. 2017:490(3):920-6.

28. Li W, Zhang X, Wang J, Li M, Cao C, Tan J, Ma D, Gao Q. TGFbeta1 in fibroblasts-derived exosomes promotes epithelial-mesenchymal transition of ovarian cancer cells. Oncotarget. 2017;8(56):96035-47.

29. Liu RT, Cao JL, Yan CQ, Wang Y, An CJ, Lv HT. Effects of LncRNA-HOST2 on cell proliferation, migration, invasion and apoptosis of human hepatocellular carcinoma cell line SMMC-7721. Biosci Rep. 2017;37(2):20160532.

30. Zhao S, Chlebowski RT, Anderson GL, Kuller LH, Manson JE, Gass M, Patterson R, Rohan TE, Lane DS, Beresford SA, et al. Sex hormone associations with breast cancer risk and the mediation of randomized trial postmenopausal hormone therapy effects. Breast Cancer Res. 2014;16(2):R30.

31. Fang $\mathrm{Q}$, Chen X, Zhi X. Long non-coding RNA (LncRNA) urothelial carcinoma associated 1 (UCA1) increases multi-drug resistance of gastric cancer via downregulating miR-27b. Med Sci Monit. 2016;22:3506-13.

32. Yoon JH, Abdelmohsen K, Srikantan S, Yang X, Martindale JL, De S, Huarte M, Zhan M, Becker KG, Gorospe M. LincRNA-p21 suppresses target mRNA translation. Mol Cell. 2012;47(4):648-55.

33. Zhou T, Gao Y. Increased expression of LnCRNA BANCR and its prognostic significance in human hepatocellular carcinoma. World J Surg Oncol. 2016;14(1):8.

34. Guo C, Song WQ, Sun P, Jin L, Dai HY. LncRNA-GAS5 induces PTEN expression through inhibiting miR-103 in endometrial cancer cells. J Biomed Sci. 2015;22:100.

35. Zhang L, Hao C, Zhai R, Wang D, Zhang J, Bao L, Li Y, Yao W. Downregulation of exosomal let-7a-5p in dust exposed- workers contributes to lung cancer development. Respir Res. 2018;19(1):235.

36. Liang WC, Fu WM, Wong CW, Wang Y, Wang WM, Hu GX, Zhang L, Xiao LJ Wan DC, Zhang JF, et al. The IncRNA H19 promotes epithelial to mesenchymal transition by functioning as miRNA sponges in colorectal cancer. Oncotarget. 2015;6(26):22513-25.

37. Wu J, Weng Y, He F, Liang D, Cai L. LncRNA MALAT-1 competitively regulates miR-124 to promote EMT and development of non-small-cell lung cancer. Anticancer Drugs. 2018;29(7):628-36.

38. Wang X, Lu X, Geng Z, Yang G, Shi Y. LncRNA PTCSC3/miR-574-5p governs cell proliferation and migration of papillary thyroid carcinoma via wnt/ beta-catenin signaling. J Cell Biochem. 2017:118(12):4745-52.

39. Mas-Ponte D, Carlevaro-Fita J, Palumbo E, Hermoso Pulido T, Guigo R, Johnson R. LncATLAS database for subcellular localization of long noncoding RNAs. RNA. 2017;23(7):1080-7.

40. Dali-Youcef N, Hnia K, Blaise S, Messaddeq N, Blanc S, Postic C, Valet P, Tomasetto C, Rio MC. Matrix metalloproteinase 11 protects from diabesity and promotes metabolic switch. Sci Rep. 2016;6:25140.

41. Xu G, Zhang B, Ye J, Cao S, Shi J, Zhao Y, Wang Y, Sang J, Yao Y, Guan W, et al. Exosomal miRNA-139 in cancer-associated fibroblasts inhibits gastric cancer progression by repressing MMP11 expression. Int J Biol Sci. 2019;15(11):2320-9.

42. Yang $H$, Jiang $P$, Liu D, Wang $H Q$, Deng Q, Niu X, Lu L, Dai H, Wang H, Yang W. Matrix metalloproteinase 11 is a potential therapeutic target in lung adenocarcinoma. Mol Ther Oncolytics. 2019;14:82-93.

43. Wang B, Hsu CJ, Lee HL, Chou CH, Su CM, Yang SF, Tang CH. Impact of matrix metalloproteinase-11 gene polymorphisms upon the development and progression of hepatocellular carcinoma. Int J Med Sci. 2018:15(6):653-8. 
44. Bai T, LiuY, Li B. LncRNA LOXL1-AS1/miR-let-7a-5p/EGFR-related pathway regulates the doxorubicin resistance of prostate cancer DU-145 cells. IUBMB Life. 2019;71(10):1537-51.

45. Yang X, Xie X, Xiao YF, Xie R, Hu CJ, Tang B, Li BS, Yang SM. The emergence of long non-coding RNAs in the tumorigenesis of hepatocellular carcinoma. Cancer Lett. 2015;360(2):119-24.

\section{Publisher's Note}

Springer Nature remains neutral with regard to jurisdictional claims in published maps and institutional affiliations.
Ready to submit your research? Choose BMC and benefit from:

- fast, convenient online submission

- thorough peer review by experienced researchers in your field

- rapid publication on acceptance

- support for research data, including large and complex data types

- gold Open Access which fosters wider collaboration and increased citations

- maximum visibility for your research: over 100M website views per year

At BMC, research is always in progress.

Learn more biomedcentral.com/submissions 